\title{
UJI SENSITIVITAS ANTIBIOTIK KOTRIMOKSAZOL TERHADAP BAKTERI Salmonella sp. DENGAN METODE MODIFIKASI KIRBY- BAUER
}

\author{
Dinar Ikhwal Prasetia $^{1 *}$, Maulin Inggraini ${ }^{2}$, Noor Andryan Ilsan ${ }^{3}$ \\ 1. Program Studi DIII Analis Kesehatan, STIKes Mitra Keluarga, Bekasi-Indonesia \\ 2. Program Studi DIII Analis Kesehatan, STIKes Mitra Keluarga, Bekasi-Indonesia \\ 3. Program Studi DIII Analis Kesehatan, STIKes Mitra Keluarga, Bekasi-Indonesia \\ *Korespondensi: Dinar Ikhwal Prasetia | STIKes Mitra Keluarga | dinarprasetia22@ gmail.com
}

\begin{abstract}
Abstrak
Pendahuluan: Salmonellosis adalah penyakit infeksi pada manusia dan hewan yang disebabkan oleh bakteri Salmonella sp.. Terapi utama yang dipakai dalam penanganan Salmonellosis adalah dengan pemberian antibiotik. Setiap daerah mempunyai pola sensitivitas Salmonella $s p$. yang berbeda. Sensitivitas antibiotik terhadap suatu bakteri sangat penting untuk menyesuaikan pengobatan terbaru dan melihat manfaat dari pengobatan sebelumnya. Tujuan dari penelitian ini adalah mengetahui sensitivitas bakteri Salmonella sp. terhadap antibiotik kotrimoksazol.

Metode: Penelitian dilakukan di Laboratorium Mikrobiologi Sekolah Tinggi Ilmu Kesehatan Mitra Keluarga Bekasi Timur pada bulan September 2017. Penelitian ini merupakan penelitian deskripstif dengan pendekatan rancangan studi cross sectional. Teknik pengambilan sampel pada penelitian ini adalah purposive sampling. Uji sensitivitas antibiotik dilakukan dengan menggunakan metode difusi cakram kertas modifikasi Kirby-Bauer. Prinsip dari metode ini adalah penghambatan terhadap pertumbuhan mikroorganisme, yaitu zona hambatan akan terlihat sebagai zona jernih disekitar daerah yang mengandung zat antibakteri kotrimoksazol. Media yang digunakan pada penelitian ini adalah Mueller Hinton Agar (MHA) dengan menggunakan standar kekeruhan MC Farland 0,5. Penilaian sensitivitas antibiotik kotrimoksazol berdasarkan ukuran zona hambatnya dengan mengukur besarnya diameter daya hambat yang terbentuk disekitar cakram kertas antibiotik tersebut. Diameter zona hambat yang terbentuk semakin besar, maka semakin besar pula sensitivitas antibiotiknya. Interpretasi hasil didasarkan pada zona hambat yang terbentuk dan disesuaikan dengan kriteria standar dari Clinical and Laboratory Standards Institute (CLSI) 2014. Jumlah sampel dalam penelitian ini sebanyak 9 sampel isolat Salmonella sp. yang berasal feses.

Hasil: Hasil uji sensitivitas antibitotik kotrimoksazol terhadap bakteri Salmonella sp. menunjukkan bahwa bakteri Salmonella sp., sensitif $100 \%$ terhadap antibiotik kotrimoksol dengan rerata diameter zona hambat $31,11 \mathrm{~mm}$.

Kesimpulan: Berdasarkan uraian kesimpulan di atas dapat dilakukan penelitian rutin untuk periode tertentu mengenai pola sensitivitas dari bakteri penyebab demam tifoid di berbagai daerah secara berkala karena masing-masing daerah mempunyai pola sensitivitas yang berbeda dan bervariasi pada waktu dan tempat yang berbeda.
\end{abstract}

Kata Kunci: Salmonella sp., Kotrimoksazol, Sensitivitas antibiotik.

Diterima 25 Juli 2019; Accepted 30 Desember 2019

\section{PENDAHULUAN}

Salmonellosis adalah penyakit infeksi pada manusia dan hewan yang disebabkan oleh bakteri Salmonella sp.. Salmonellosis dapat disebabkan oleh beberapa varian Salmonella, yakni Salmonella typhi, Salmonella cholera, dan mungkin Salmonella paratyphi A dan Salmonella paratyphi B yang menjadi penyebab infeksi utama pada manusia. Bakteri yang paling banyak menginfeksi dan menyebabkan penyakit adalah Salmonella typhi yakni penyebab demam tifoid. Penyakit tersebut berkaitan erat dengan kualitas yang berasal dari kebersihan pribadi dan sanitasi lingkungann seperti kebersihan makanan dan minuman yang rendah, kebersihan tempat-tempat umum (rumah makan, restoran) yang kurang, dan perilaku masyarakat yang tidak mendukung untuk hidup sehat (Brooks, et al., 2005).

Menurut Ochiai, et al. (2008) tercatat bahwa kejadian Salmonellosis akibat Salmonella typhi di Indonesia mencapai 33,1 per 1000 dengan kejadian yang sama pada semua tingkat usia. Dengan demikian, kejadian Salmonellosis bukan merupakan kejadian langka di Indonesia. Terapi utama yang dipakai dalam penanganan salmonellosis adalah dengan pemberian antibiotik. Berbagai spesies Salmonella resisten terhadap antibiotik konvensional seperti ampisilin, kloramfenikol, kuinolon dan sefalosporin berspketrum luas, serta kotrimoksazol dilaporkan meningkat frekuensinya dalam beberapa area di seluruh dunia. Pola resistensi yang terjadi sangat tergantung dari pola atau sifat bakteri, penggunaan antibiotik, penatalaksanaan 
penyakit serta kecepatan resistensi bakteri terhadap antibiotik (Perdana \& Setyawati, 2016).

Trimethoprim-Sulfametoxazole dikenal sebagai kotrimoksazol yang digunakan untuk mengobati berbagai infeksi. Kotrimokxazol umumnya menyebabkan kematian bakteri dengan menghalangi pembuatan folat oleh bakteri. Kotrimoksazol adalah antibiotik kombinasi dari golongan sulfonamide yang sangat umum digunakan. (Sari dkk., 2015).

Penelitian sebelumnya oleh Katarnida pada tahun 2013 tentang Pola sensitifitas Bakteri dan Penggunaan Antibiotik di kota Jakarta, diperoleh hasil bahwa antibiotik sefotaksim, seftriakson, kloramfenikol, dan kotrimoksazol memiliki sensitivitas yang tinggi terhadap bakteri Salmonella sp. Dengan persentase masing-masing sebesar 100\% dari 11 hasil kultur Salmonella sp. yang ditemukan. Rata-rata diameter zona hambat Salmonella sp. sebesar $32.5 \mathrm{~mm}$.

Berdasarkan mekanisme kerja antibiotik kotrimoksazol termasuk kedalam kelompok menghambat sintesa folat bakteri, yaitu bakteri tidak dapat mengabsorbsi asam folat, tetapi harus membuat asam folat dari Para-Aminobenzoic Acid (PABA), petridin, dan glutamate. Sedangkan pada manusia, asam folat merupakan vitamin dan kita tidak dapat mensistensis asam folat. Hali ini menjadi suatu target yang baik dan selektif untuk senyawa-senyawa antimikroba (Febiana, 2012). Setiap daerah mempunyai pola senstivitas Salmonella sp. yang berbeda, sehingga perlu dilakukan uji sensitivitas secara berkala karena pola sensitivitas pada waktu dan tempat yang berbeda. Meneliti pola sensitivitas antibiotik terhadap suatu bakteri sangat penting untuk menyesuaikan pengobatan terbaru dan melihat manfaat dari pengobatan sebelumnya (Juwita dkk., 2013).

Uji sensitivitas antibiotik harus dikerjakan dengan metode akurat dan teliti, yang hasilnya harus dapat diterapkan langsung pada keadaan klinis. Teknik modifikasi difusi cakram Kirby-Bauer, dapat direkomendasikan untuk tujuan klinis dengan mempertimbangkan kesederhanaan teknik dan ketelitiannya. Metode ini terutama cocok digunakan untuk bakteri yang termasuk famili Enterobacteriaceae, tetapi metode ini juga dapat direkomendasikan sebagai metode serbaguna bagi semua patogen yang tumbuh cepat. Metode ini telah disesuaikan untuk bakteri-bakteri sukar tumbuh (fastidious) yang paling penting secara klinis, tetapi tidak untuk anaerob obligat dan mikrobakteria. (Vandepitte, et al., 2003). Berdasarkan pemaparan yang ada maka penulis tertarik untuk melakukan penelitian tentang Uji Sensitivitas Antibiotik Kotrimoksazol Terhadap Bakteri Salmonella sp. dengan Metode Modifikasi Kirby-Bauer.

\section{METODE}

Penelitian ini merupakan penelitian deskriptif dengan pendekatan rancangan studi cross sectional. Teknik pengambilan sampel pada penelitian ini adalah purposive sampling. Penelitian ini dilakukan di Laboratorium Mikrobiologi Sekolah Tinggi Ilmu Kesehatan Mitra Keluarga Bekasi Timur. Penelitian ini dilakukan pada bulan September 2017. Sampel yang digunakan dalam penelitian ini merupakan isolat murni bakteri Salmonella sp. yang berasal dari sampel feses di Yayasan Dinamika Indonesia dan Tunas Mulia, Bantar Gebang serta telah dibiakkan di Laboratorium Mikrobiologi Sekolah Tinggi Ilmu Kesehatan Mitra Keluarga Bekasi Timur.

Tes sensitivitas dilakukan dengan metode difusi modifikasi Kirby-Bauer pada media agar Mueller Hinton. Prosedur dalam penelitian ini dimulai dengan tahap penanaman bakteri pada media Nutrien Agar, kemudian dilakukan pengukuran kerapatan bakteri dengan cara isolat murni dibuat inokulum dengan menggunakan ose, 3-5 permukaan koloni dari tiap organisme yang sama diambil untuk diuji, koloni dipindahkan ke sebuah tabung yang berisi salin. Tahap selanjutnya adalah uji resistensi antimikroba, dengan cara tabung salin yang sudah terisi oleh bakteri dibandingkan dengan dengan standar kekeruhan Mc.Farland dan atur kekeruhan suspensi uji sampai sama dengan larutan standar kekeruhan tersebut. Jika belum sama, ditambahkan kembali bakteri kedalam larutan garam fisiologis, tetapi jika terlalu pekat tambahkan larutan garam fisiologis kembali. Pengaturan kekeruhan inokulum yang tepat penting untuk memastikan hasil pertumbuhan yang merata atau hampir merata (Vandepitte, et al., 2003).

Bakteri yang terdapat di dalam media salin tersebut diinokulasikan dengan cara mencelupkan cottonbud steril ke dalam media Mueller Hinton Agar (MHA). Terlebih dahulu ditiriskan dengan cara memutar-mutarkan cottonbud di sisi tabung di batas cairan agar tidak terdapat bakteri berlebih. Cottonbud distreak ke seluruh permukaan media MHA sebanyak tiga kali, dengan memutar agar dengan sudut $60^{\circ}$ setelah setiap pengolesan. Tahap akhir, Cottonbud dilewatkan ke sekelilling pinggiran permukaan agar. Biarkan media mengering selama beberapa menit pada suhu ruang dengan cawan tertutup. Cakram 
antimikroba dapat diletakkan pada lempeng yang telah diinokulasikan dengan menggunakan sepasang penjepit steril. Media bakteri diinkubasi selama $1 \times 24$ jam pada suhu $37{ }^{\circ} \mathrm{C}$, lalu diameter tiap zona harus diukur dan dicatatat dalam mm (Vandepitte, et al., 2003).

Tabel 1. Grafik interpretasi ukuran zona teknik Kirby-Bauer yang dimodifikasi (CLSI, 2014)

\begin{tabular}{llll}
\hline Agen antimikroba & Resisten & Intermediet & Sensitif \\
\hline Kotrimoksa-zol & $<10 \mathrm{~mm}$ & $11-15 \mathrm{~mm}$ & $>16 \mathrm{~mm}$ \\
\hline
\end{tabular}

Data yang didapat dari penelitian ini dikumpulkan berdasarkan pengamatan hasil pengukuran zona hambat pertumbuhan Salmonella sp. setelah pemberian antibiotik kotrimoksazol, kemudian diukur menggunakan penggaris dalam satuan millimeter $(\mathrm{mm})$ dan dicatat. Data yang didapat kemudian dianalisis secara deskriptif dan dibandingkan dengan diameter standar menurut Clinical and Laboratory Standrads Institute (CLSI) apakah tergolong sensitif, intermediate, atau resisten.

\section{HASIL}

Hasil penelitian ini telah disesuaikan dengan kriteria standar dari Clinical and Laboratory Standards Institute (CLSI) dengan tingkat sensitivitas $100 \%$ dari antibiotik kotrimoksazol. Diameter rerata yang terbentuk dari antibiotik kotrimoksazol sebesar $31,11 \mathrm{~mm}$. Besaran rerata diameter daya hambat yang terbentuk dan hasilnya dapat dilihat pada tabel 2.

Tabel 2. Hasil pengukuran diameter zona hambat, iterpretasi dan rerata dari uji sensitivitas antibiotik

Kotrimoksazol

\begin{tabular}{ccc}
\hline Jumlah Pengulangan & Diameter Zona Hambat & Interpretasi \\
\hline 1 & $30 \mathrm{~mm}$ & Sensitif \\
2 & $32 \mathrm{~mm}$ & Sensitif \\
3 & $32 \mathrm{~mm}$ & Sensitif \\
4 & $32 \mathrm{~mm}$ & Sensitif \\
5 & $32 \mathrm{~mm}$ & Sensitif \\
6 & $30 \mathrm{~mm}$ & Sensitif \\
7 & $30 \mathrm{~mm}$ & Sensitif \\
8 & $32 \mathrm{~mm}$ & Sensitif \\
9 & $30 \mathrm{~mm}$ & Sensitif \\
\hline Jumlah & 280 & \\
Rerata & $31.11 \mathrm{~mm}$ & \\
\hline
\end{tabular}

Hasil yang didapatkan dari pengukuran zona hambat menunjukkan bahwa antibiotik kotrimoksazol memiliki zona hambat dengan rerata sebesar $31,11 \mathrm{~mm}$. Interpretasi ukuran zona hambat untuk sensitivitas menurut Clinical and Laborratory Standards Institute (CLSI) lebih dari $16 \mathrm{~mm}$. Hasil pengukuran didapatkan bahwa antibiotik kotrimoksazol termasuk ke dalam kriteria sensitif dengan persentase senitivitas dari antibiotik uji tersebut sebesar $100 \%$.

\section{PEMBAHASAN}

Sensitivitas antibiotik Kotrimoksazol yang didapatkan pada penelitian ini memiliki respon yang baik dengan persentase $100 \%$. Penelitian ini sesuai dengan penelitian yang dilakukan oleh Katarnida pada tahun 2013 dalam penelitiannya yang dilakukan di Jakarta menjelaskan bahwa pada uji sensitivitas antibiotik, hasil kultur dari Salmonella sp. menunjukkan respon yang baik terhadap beberapa antibiotik. Respon tersebut menunjukkan bahwa ditemukan hasil sensitif 100\% terhadap antibiotik sefotaksim, seftriakson, kloramfenikol, dan kotrimoksazol (Katarnida dkk., 2013).

Hasil penelitian ini sesuai dengan hasil penelitian yang dilakukan oleh Joshi pada tahun 2012 spesies Salmonella masih sensitif terhadap antibiotik kotrimoksazol dengan persentase $100 \%$. Penelitian yang dilakukan oleh Perdana pada tahun 2016 di RSUD Ulin Banjarmasin memberikan hasil bahwa tingkat sensitivitas antibiotik kotrimoksazol dengan persentase $80 \%$. Penelitian lain yang dilakukan oleh Juwita pada tahun 2013 menunjukkan tingkat sensitivitas antibiotik secara in-vitro terhadap Salmonella sp. yang dilakukan di kota Banjarmasin memberikan hasil bahwa tingkat sensitivitas antibiotik Kotrimoksazol 
dengan persentase sebesar $79.16 \%$. Penelitian yang dilakukan oleh Sandika pada tahun 2017 tentang tes sensitivitas dari 317 sampel Salmonella sp. terhadap antibiotik Kotrimoksazol didapatkan $92.11 \%$ sensititif. Hasil yang bevariasi ini disebabkan karena pola sensitivitas suatu bakteri akan selalu berubah di tempat dan waktu yang berbeda. Hal tersebut bisa disebabkan oleh beberapa hal, seperti kerasionalan dalam penggunaannya dan kepatuhan penderita dalam meminum obat. Keberagaman tingkat sensitivitas dapat diakibatkan oleh banyaknya faktor - faktor yang mempengaruhi tingkat sensitivitas suatu antibiotik terhadap bakteri Salmonella sp. Faktor - faktor tersebut dapat berupa penggunaan antibiotik dalam jangka waktu yang lama, penggunaan yang tidak tepat, kepatuhan pasien dalam meminum obat, dan masih banyak lagi baik dari tingkat sel bakteri maupun tingkat ekonomi pasien (Juwita dkk., 2013)

Mekanisme dari antibiotik kotrimoksazol adalah aktivitas antibakteri kombinasi antara sulfametoksazol dan trimethoprim (kotrimoksazol) berdasarkan kerjanya pada dua tahap yang berurutan pada reaksi enzimatik untuk pembentukan asam tetrahidrosulfat. Sulfonamide menghambat masuknya ParaAminobenzoic Acid (PABA) ke dalam molekul asam folat dan trimethoprim menghambat terjadinya reaksi reduksi dari dhirofolat menjadi tetrahidrofolat (Siswandono, 1995).

Antibiotik kotrimoksazol sebagai obat pilihan atau "drug of choice" memberikan respon yang baik pada penelitian ini. Sehingga penggunaan antibiotik kotrimoksazol sebagai "drug of choice" dapat terus dilanjutkan dengan tetap memperhatikan efek samping dari penggunaan obat tersebut. Hasil tersebut telah sesuai dengan teori yang ada dan dikemukakan oleh beberapa penelitian sebelumnya, antara lain oleh Katarnida pada tahun 2013 tentang pola sensitivitas bakteri dan penggunaan antibiotik di kota Jakarta, diperoleh hasil bahwa antibiotik kotrimoksazol memiliki sensitivitas yang tinggi terhadap bakteri Salmonella sp. dengan persentase sebesar 100\% dan rerata diameter yang terbentuk sebesar $32.5 \mathrm{~mm}$. Kotrimoksazol sebagai antibiotik lini kedua apabila kloramfenikol sudah resisten, sehingga tingkat sensitivitas antibiotik kotrimoksazol terhadap bakteri Salmonella sp. masih sangat tinggi (Katarnida dkk., 2013).

\section{KESIMPULAN}

Hasil dari penelitian ini dapat disimpulkan bahwa antibiotik Kotrimoksazol memiliki sensitivitas yang tinggi terhadap bakteri Salmonella sp. dengan persentase 100\% dan daya hambat yang terbentuk sebesar $31.11 \mathrm{~mm}$. Berdasarkan uraian kesimpulan di atas dapat dilakukan penelitian rutin untuk periode tertentu mengenai pola sensitivitas dari bakteri penyebab demam tifoid di berbagai daerah secara berkala karena masing-masing daerah mempunyai pola sensitivitas yang berbeda dan bervariasi pada waktu dan tempat yang berbeda.

\section{REFERENSI}

Brooks, G. F., Butel, J. S., \& Morse, S. A. 2005. Mikrobiologi Kedokteran. Edisi 1. Salemba Medika, Jakarta.

CLSI. 2014. Performance Standards for Antimicrobial Susceptibility Testing; Twenty-Fourth Informational Supplement (CLSI document M100-S24 ed.). Wayne, PA: Clinical and Laboratory Standards Institute.

Febiana, T. 2012. Kajian Rasionalitas Penggunaan Antibiotika Di BAngsal Anak RSUP Dr. Kariadi Semarang Periode Agustus-Desember 2011. Skripsi, Fakultas Kedokteran, Universitas Diponogero, Semarang.

Joshi, B., Keyal, K., Pandey, R., \& Shrestha, B. 2012. Clinical Profile and sensitivity Pattern of Salmonella Serotypes in Children: A Hospital Based Study. Original Article. 31 (3) : 180-183.

Juwita, S., Hartoyo, E., \& Budiarti, L. Y. 2013. Pola Resistensi In Vitro Salmonella typhi Terhadap Antibiotik Kloramfenikol, Amoksilin, dan Kontrimoksazol. Berkala Kedokteran. 9 : 25-34.

Katarnida, S. S., Karyanti, M. R., \& Katar, Y. 2013. Pola Sensitivitas Bakteri dan Penggunaan Antibiotik. Sari Pediatri. 15 (2) : 122-126.

Ochiai, R. L., Acosta, C.J., Danovaro, H. M., Baiqing, D., Ali, M., Shin, S., Study Group, D. Y. 2008. A Study of Typhoid Fever in Five Asian Countries: Disease BUrden and Implications for Controls. Korea: Bulletin of the World Health Organization. 86(4): 323-360.

Perdana, R., \& Setyawati, T. 2016. Uji In-Vitro Sensitivitas Antibiotik Terhadap Bakteri Salmonella typhi Di kota Palu. Medika Tadulako, Jurnal Ilmiah Kedokteran. 3 (1) : 11-22. 


\section{Jurnal Mitra Kesehatan (JMK)}

DOI: $10.47522 /$ jmk.v2i1.23

Sandika, J., \& Suwandi, J. F. 2017. Sensitivitas Salmonella thypi Penyebab Demam Tifoid terhadap Beberapa Antibiotik. Majority. $6: 41-45$.

Sari, W. P., Darmawati, S., \& Prastiyanto, E. M. 2015. Perbedaan Hasil Uji Kepekaan Salmonella typhi Menggunakan Mueller Hinton Agar dan Nutrient Agar dengan Antibiotik Ampicilin, Ciprofloxacin dan Trimethoprim-Sulfamethoxazole. Skripsi, Universitas Muhammadiyah, Semarang.

Siswandono, D. 1995. Kimia Medisinal. Airlangga University Press, Surabaya.

Vandepitte, J., Verhaegen, J., Engbaek, K., Rohner, P., Piot, P., \& Heuck, C. C. 2003. Basic Laboratory Procedures In Clinical Bacteriology (2003 ed.). Geneva, Switzerland: World Health Organization. 